\title{
Preparation of nano disperse dye based on benzopyran in one pot reaction using microwave irradiation and its appliance in textile printing
}

\author{
K. A. Ahmed ${ }^{1}$ - H. M. El-Hennawi ${ }^{1}$ A. A. Shahin ${ }^{1}$ A. A. Ragheb ${ }^{1}$
}

(c) Springer Nature Switzerland AG 2019

\begin{abstract}
This paper aims to synthesis some novel of benzopyran derivatives using high efficient, solvent free, excellent yield, one pot multicomponent reaction via microwave technique. The prepared compounds are subjected to ultra-sonication to reduce their particle size to nano size and used as a pigment in printing of polyester/cotton, polyester and linen fabrics the fastness properties of the printed fabrics are very good. The structures of prepared pigment are confirmed using (element analysis, IR, H-NMR and MS). The size of prepared and treated dyes are identify by TEM.
\end{abstract}

Graphic abstract Graphic abstract explain the suggested scheme for synthesise the hyper branched compound I with TEM image for the different resulting compounds with different moieties before and after sonication.

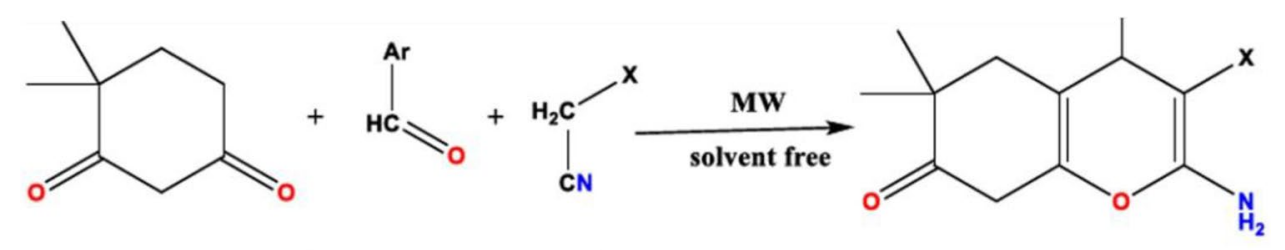

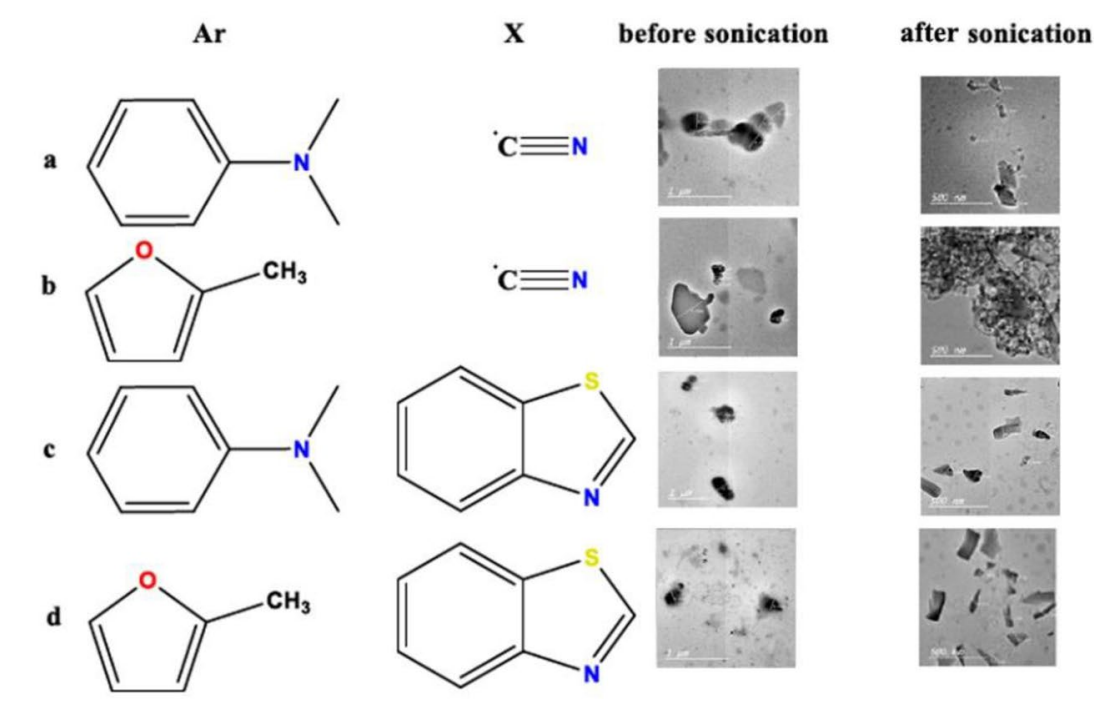

H. M. El-Hennawi, skybird740@yahoo.com | ${ }^{T}$ Textile Industries Research Division, Dyeing, Printing and Textile auxiliaries Department, National Research Centre (Scopus Affiliation ID 60014618), 33-El-Behouth St. (former El-Tahrir str.), Dokki, P.O. 12622, Giza, Egypt. 
Keywords Nano disperse dye - Benzopyran - Microwave and textile printing

\section{Introduction}

Benzopyran compounds are belongs according to its structure to natural product which have a lot of interesting biological and pharmaceutical application [21,38]. 4- $\mathrm{H}$-chromene derivatives received a considerable attention in the last decades because it act as starting compounds for anticancer, anticoagulant, and biodegradable agrochemicals. Only few research articles reported it as a pigment without further application [13, 33].

There are a lot of reported methods for preparation of 4-H-chromene (benzopyran) derivatives via multi-component reaction including of catalyst such as acetic acid, and organo-catalyst. These methods leads to low yield, waste time $[14,35,36,51]$.

Disperse dye normally known as an extensively water insoluble dye with an affinity to hydrophobic fibres only. They are usually utilized in the textile industry to impart a colour to synthetic fibers, for example polyester, acrylic and acetate. Before using, disperse dye converted to a low particle size dispersed in water and added to treatment bath during textile coloration process.

Increasing awareness of environmental issues around the world make various treatments such as UV, ultrasonic, gamma radiation and microwave in the light spot for many scientist who are working in the field of textile wet treatments (pre-treatment and dyeing) to improve the quality of the dyed fabrics and reduce environmental pollution in the same time. UV radiation is mainly used in the pretreatment of both the fabric and dye solution separately to lower the dyeing conditions (time and temperature) and enhance the colour strength and fastness properties of treated fabrics $[9,16,20,22,27,28]$. The same results were noticed by using the gamma radiation and plasma on different fabrics $[8,44]$. The microwave radiation application in textile takes the attention of researchers as an alternative eco-friendly heating system. Shahid et al. improve the color strength and fastness properties of polyester fabric dyed with disperde Yellow 211 dye under the influence of microwave for 6 min [10, 11, 15, 23]. Limited study has been performed on the effect of radiation on the synthesis of organic dyes itself. The synthesis of benzopyran is obtained from different kinds of starting materials using basic catalysts [52] or by condensation reactions [30, 40, 50]. Most of these methods has limitations such as long time of reaction, consume an expensive strongly basic materials, tedious work-up and low products. Chaturvedi et al. [19] employ the microwave radiation in the synthesis of benzopyrans from substituted acetophenones and keto compounds mediated by Triton-B under solvent-free conditions and mild condition in one pot reaction given excellent yield.

Introduction of various radiations, for example, ultraviolet [41] and microwave [32] treatment which can impart better color fastness properties to the modified fabrics $[12,17,43]$. Some researchers have found that, microwave treatment improve the extraction of color from their natural source, which offers deep shading to the fabrics [32]. Microwave can equitably and effectively enter into a medium and consistently heat the substance $[31,34]$. During microwave treatment, polar groups of the medium are excited which results into heat creation. Past investigations have demonstrated that, microwave treatment didn't change the micro fibrils of cellulose [49] and the physical properties for example, wrinkling and tensile strength were highly improved.

Ultrasound (US) improve a wide range of both chemical and physical processes; mostly because of the phenomenon known as cavitation inside the liquid medium that is the development and breakdown of tiny bubbles which can create a hot spots [14], for example restricted high temperature and pressure, shock waves and extremely shear forces equipped for breaking bonds. Many researchers have been investigate this method in the textile coloration as it is a noteworthy wet process, which required high energy, water and releases huge effluent to the environment. In addition any enhancements in coloration processes are generally ascribed to the cavitation phenomena $[35,51]$ and, as an outcome, other mechanical and chemical impacts are as listed below:

- Decreasing any agglomerations with high molecular mass;

- Remove any dissolve/entrap air from cavities;

- Accelerate the diffusion rate of dye;

- Powerful agitation of the liquid;

- Breaking down the diffusion layer interfaces;

- Producing a free radicals.

This work combine the using of microwave radiation in the preparation of some novel heterocyclic compounds based on 4-Hchromene derivatives using in one pot multicomponent reaction then the produced disperse dyes were subjected to sonication to reduce its particle size and be applied as nano-pigment in printing of linen, polyester and cotton/polyester fabrics.

The aim of this work is to print nature fibre as linen and cotton/polyester blend using the solvent free nano disperse dye prepared with high colour strength and good to excellent fastness properties via pigment printing 
technique. The advantages of both economic and environmental, points of view using of solvent free technique and green tool as microwave are very interesting. So this article report preparation of some novel heterocyclic compounds based on 4-Hchromene derivatives using eco-friendly techniques (solvent free one pot multi-component reaction and microwave heating). The prepared compounds are sonicated to reduce its particle size and used as nano-pigment in printing of linen, polyester and cotton/polyester fabrics.

\section{Experimental}

\subsection{Materials}

Linen, cotton/polyester. (40/60) and polyester fabric are supplied by a private sector company. Malononitrile, 2-(benzo[d]thiazol-2-yl)acetonitrile, 2-methyl cyanobenzothiazole, dimedone and benzaldehyde derivatives, tetramethyl silane, sodium dihydrogen phosphate dehydrate, all chemicals were purchased from Merck (Germany) and were used without further purification. Commercial binder, namely EBCAPRINTTB manufactured by Egyptian British Company was used. Commercial synthetic thickener namely Printofix thickener MTB 01 liq. (Clariant Company).

\subsection{Synthesis}

A mixture of malononitrile, or 2-methyl cyanobenzothiazole $2(0.01 \mathrm{mmol})$, dimedone $3(0.01 \mathrm{mmol})$ and benzaldehyde derivatives $1(0.01 \mathrm{mmol})$ were mixed and subjected to microwave radiation (multimode Milestone $\mathrm{MW}$ reactor with a frequency of $2.45 \mathrm{GHz}$ and maximum MW power of $1200 \mathrm{~W}$ ) for $10 \mathrm{~min}$. The reaction progress was observed using thin layer chromatograph (TLC). After the reaction was completed, the mixture was poured into ice water then filtered (Fig. 1).

\subsection{Ultra-sonication of pigment}

A $3 \mathrm{~g}$ of disperse dyes were suspended in $100 \mathrm{ml}$ water under stirring with ultrasonic stirrer; $80 \%$ power and 35 frequency (SONICS \& MATERIALS, INC), Model: VCX750, Volts: $230 \mathrm{~V}$ AC50160 HZNOM, USA) for $30 \mathrm{~min}$ at room temperature then added to the printing paste according to the following recipe.

\begin{tabular}{ll}
\hline Prepared dye & $\begin{array}{c}20 \mathrm{~g} \text { of } \\
\text { dye } \\
\text { suspend }\end{array}$ \\
Urea & $2.5 \mathrm{~g}$ \\
Synthetic thickener & $50 \mathrm{~g}$ \\
Binder & $5 \mathrm{~g}$ \\
Sodium dihydrogen phosphate dehydrate & $0.5 \mathrm{~g}$ \\
Distilled water & $\mathrm{Y}$ \\
Total & 100 \\
\hline
\end{tabular}

\subsection{Characterisation}

The melting points for synthesized dyes were investigated using a melting point apparatus. FT-IR, nuclear magnetic resonance, Mass spectra and transmission electron microscope of the untreated and treated samples were recorded using FT-IR spectrometer (JASCO connected with ATR), Varian 400 or Wilmad 270-MHz spectrometer, Varian MAT112 spectrometer and JEOL JEM-1230 equipment respectively. Perkin Elmer double-beam spectrophotometer is used to measure Absorption spectra.

Fig. 1 Scheme for synthesis of hyper branched composite I

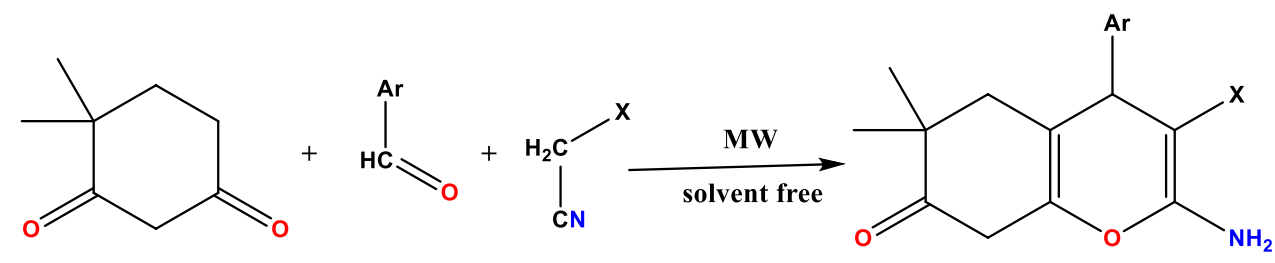

Ar

a<smiles>CN(C)c1ccccc1</smiles>

b<smiles>Cc1ccco1</smiles>

x<smiles>[C]=N</smiles>

${ }^{\mathrm{C}} \equiv \mathrm{N}$
Ar<smiles>CN(C)c1ccccc1</smiles>

d<smiles>Cc1ccco1</smiles>

X<smiles>c1ccc2scnc2c1</smiles><smiles>c1ccc2scnc2c1</smiles>

SN Applied Sciences 
Colour strength values of the dyed fabrics was measured using reflection spectroscopy (Hunter Lab UltraScanPRO USA, 2007) at the wavelength of the maximum absorbance and it was expressed as $\mathrm{K} / \mathrm{S}$ which assessed by applying the Kubelka-Munk equation $[6,7,22,24,25,45$, 46]. Fastness properties of dyed fabric to washing, crocking (dry and wet rubbing), perspiration and light were determined according to standard methods AATCC Test Method 61-2007, AATCC Test Method 8-2007, AATCC Test Method 15-2013, AATCC Test Method (16-2004) respectively. The evaluation established using the blue scale as reference of colour change [1-4, 26, 27, 47, 48].

\section{Result and discussion}

\subsection{Synthesis}

The present research deals with a novel synthesis of functionalized heterocyclic compounds using 4-chromene (benzopyran) derivatives through the reaction of malononitrile, or 2-(benzo[d]thiazol-2-yl)acetonitrile (2), dimedone (3) and benzaldehyde (1) derivatives in a microwave (Fig. 1). The benzopyran derivatives were synthesised via Michael adduct, after that, water elimination and dehydrogenation was carried out using microwave irradiation (Fig. 1). The chemical structure of the pigments were confirmed using different techniques; element analysis, IR, ${ }^{1} \mathrm{H}$-NMR and mass spectral $[5,18,37,42]$. The result was illustrated in Tables 1,2 and 3.

\subsection{Effect of sonication on the particle size of the pigment}

It is clear from TEM images (Fig. 2a-h) that the sonication reduced the particle size over all the compounds 4a-d from micro scale to nano-scale. The results of transmission electron microscope of nano-benzopyran pigment presented a very homogeneous morphology with quite uniform particle size distribution. The particle size diameters obtained were in the range of $25-70 \mathrm{~nm}$. The conversion of several benzopyran dyes into nano-sized organic pigment has been achieved mechanically via miniaturization using ultrasonic processor for $30 \mathrm{~min}$ at
Table 1 Physical and analytical data of synthesized dyes $\mathbf{4 a - d}$

\begin{tabular}{lllllll}
\hline & Molecular formula & M.wt & Colour & Yield \% & $\lambda(\mathrm{nm})$ & m.p \\
\hline 4a & $\mathrm{C}_{20} \mathrm{H}_{23} \mathrm{~N}_{3} \mathrm{O}_{2}$ & 337 & Greenish yellow & 97 & 375 & 222 \\
4b & $\mathrm{C}_{17} \mathrm{H}_{20} \mathrm{~N}_{2} \mathrm{O}_{3}$ & 300 & Yellow & 97 & 370 & 219 \\
4c & $\mathrm{C}_{26} \mathrm{H}_{27} \mathrm{~N}_{3} \mathrm{O}_{2} \mathrm{~S}$ & 445 & Yellow & 94 & 380 & 230 \\
4d & $\mathrm{C}_{23} \mathrm{H}_{24} \mathrm{~N}_{2} \mathrm{O}_{3} \mathrm{~S}$ & 408 & Yellow & 94 & 382 & 232 \\
\hline
\end{tabular}

\begin{tabular}{|c|c|c|c|c|c|c|c|c|c|c|c|}
\hline \multirow[t]{3}{*}{ Compounds } & \multirow{2}{*}{\multicolumn{2}{|c|}{$\begin{array}{l}\text { FT-IR (KBr, } \\
\left.\mathrm{cm}^{-1}\right)\end{array}$}} & \multicolumn{8}{|c|}{ Element analysis } & \multirow[t]{3}{*}{ Mass spectra } \\
\hline & & & \multicolumn{4}{|c|}{ Theoretical (\%) } & \multicolumn{4}{|c|}{ Found (\%) } & \\
\hline & $\mathrm{NH}_{2}$ & $\mathrm{C}=\mathrm{O}$ & $\mathrm{C}$ & $\mathrm{H}$ & $\mathrm{N}$ & $\mathrm{O}$ & $\mathrm{C}$ & $\mathrm{H}$ & $\mathrm{N}$ & $\mathrm{O}$ & \\
\hline $4 a$ & 3450 & 1650 & 71.19 & 6.87 & 12.45 & 9.48 & 71.11 & 6.77 & 12.40 & 9.39 & 336 \\
\hline $4 b$ & 3456 & 1640 & 67.98 & 6.71 & 9.33 & 15.98 & 67.88 & 6.69 & 9.21 & 15.94 & 299 \\
\hline $4 c$ & 3440 & 1667 & 70.08 & 6.11 & 9.43 & 7.18 & 70.01 & 6.08 & 7.11 & 6.05 & 444 \\
\hline 4d & 3400 & 1670 & 67.62 & 5.92 & 6.86 & 11.75 & 67.55 & 5.90 & 6.84 & 11.65 & 407 \\
\hline
\end{tabular}

Table 2 Elemental analysis, mass and IR spectral data of synthesized dyes $\mathbf{4 a - d}$

Table $3{ }^{1} \mathrm{H}$-NMR spectral data of the synthesized dyes $\mathbf{4 a - d}$

\begin{tabular}{|c|c|}
\hline & ${ }^{1} \mathrm{H}-\mathrm{NMR}$ \\
\hline $4 a$ & $\begin{array}{l}1.25\left(6 \mathrm{H}, \mathrm{s}, 2-\mathrm{CH}_{3}\right), 3.06\left(6 \mathrm{H}, \mathrm{s}, 2-\mathrm{CH}_{3}\right), 3.17\left(2 \mathrm{H}, \mathrm{s}, \mathrm{CH}_{2}\right), 2.29\left(2 \mathrm{H}, \mathrm{s}, \mathrm{CH}_{2}\right), 3.94(1 \mathrm{H}, \mathrm{s}, \mathrm{CH}), 8.51\left(2 \mathrm{H}, \mathrm{s}, \mathrm{NH}_{2}\right), 6.68-6.97(4 \mathrm{H}, \mathrm{m}, \text { aromatic } \\
\text { protons) }\end{array}$ \\
\hline $4 b$ & $\begin{array}{l}1.25\left(6 \mathrm{H}, \mathrm{s}, 2-\mathrm{CH}_{3}\right), 2.3\left(3 \mathrm{H}, \mathrm{s}, \mathrm{CH}_{3}\right), 3.17\left(2 \mathrm{H}, \mathrm{s}, \mathrm{CH}_{2}\right), 2.32\left(2 \mathrm{H}, \mathrm{s}, \mathrm{CH}_{2}\right), 4.17(1 \mathrm{H}, \mathrm{s}, \mathrm{CH}), 8.59\left(2 \mathrm{H}, \mathrm{s}, \mathrm{NH}_{2}\right), 6.14-7.58(4 \mathrm{H} \text {, m, aromatic } \\
\text { protons) }\end{array}$ \\
\hline 4c & $\begin{array}{l}1.28\left(6 \mathrm{H}, \mathrm{s}, 2-\mathrm{CH}_{3}\right), 3.11\left(6 \mathrm{H}, \mathrm{s}, 2-\mathrm{CH}_{3}\right), 3.19\left(2 \mathrm{H}, \mathrm{s}, \mathrm{CH}_{2}\right), 2.31\left(2 \mathrm{H}, \mathrm{s}, \mathrm{CH}_{2}\right), 3.89(1 \mathrm{H}, \mathrm{s}, \mathrm{CH}), 8.91\left(2 \mathrm{H}, \mathrm{s}, \mathrm{NH}_{2}\right), 6.64-8.18(4 \mathrm{H}, \mathrm{m}, \text { aromatic } \\
\text { protons) }\end{array}$ \\
\hline 4d & $\begin{array}{l}1.27\left(6 \mathrm{H}, \mathrm{s}, 2-\mathrm{CH}_{3}\right), 2.5\left(3 \mathrm{H}, \mathrm{s}, \mathrm{CH}_{3}\right), 3.21\left(2 \mathrm{H}, \mathrm{s}, \mathrm{CH}_{2}\right), 2.21\left(2 \mathrm{H}, \mathrm{s}, \mathrm{CH}_{2}\right), 4.21(1 \mathrm{H}, \mathrm{s}, \mathrm{CH}), 8.89\left(2 \mathrm{H}, \mathrm{s}, \mathrm{NH}_{2}\right), 614-8.12(6 \mathrm{H}, \mathrm{m} \text {, aromatic } \\
\text { protons) }\end{array}$ \\
\hline
\end{tabular}


Fig. 2 TEM image 1 compound a Compound 4 a before sonication $\mathbf{b}$ Compound $\mathbf{4 a}$ after sonication $\mathbf{c}$ Compound $\mathbf{4 b}$ before sonication $\mathbf{d}$ Compound 4b after sonication e Compound $\mathbf{4 c}$ before sonication $\mathbf{f}$ Compound $\mathbf{4 c}$ after sonication g Compound $\mathbf{4 d}$ before sonication $\mathbf{h}$ Compound $\mathbf{4 d}$ after sonication
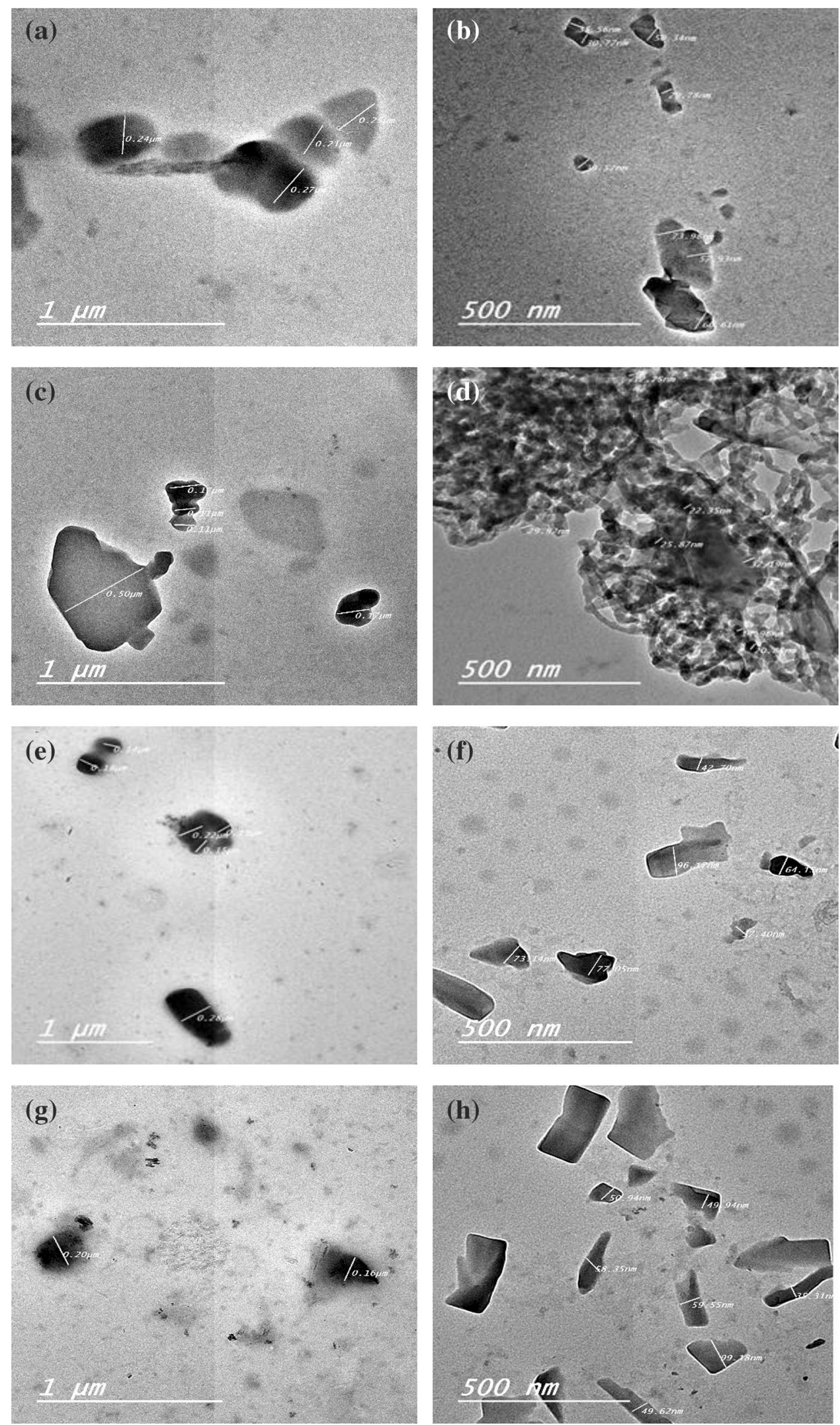
room temperature. This study also investigated the use of the prepared nano-pigment dispersion in printing (linen, polyester and its blend with cotton) with pigment printing paste in presence of binder using thermofixation. The size of nano-pigment obtained and the colour strength values $(\mathrm{K} / \mathrm{S})$ are greatly affected by the molecular structure of the prepared benzopyran dyes.

\subsection{Colour strength and fastness properties}

The colour strength of the pigment printed polyester, linen, and polyester/cotton fabrics using the synthesized pigment (before and after sonication is represented in Tables 4 and 5. It's clear from the tables that all pigment (with normal size) possesses good colour strength value ranging from 8 to 10 . Reducing the particle size over all pigments leads to high increasing in $\mathrm{K} / \mathrm{S}$ values ranging from 12 to 14.7 over all compounds.
To determine the colour parameters and the colour difference of printed fabrics, CIE lab system is used where, $(L)$ values reefer to lightness-darkness values from 100 to 0 representing white to black, (a) value run from negative (green) to positive (red) and (b) values run from negative (blue) to positive (yellow) and the total colour difference is given by $\Delta \mathrm{E}$ from Tables 4 and 5 it can be noticed that the $(L)$ values decrease in all nano-sized printed samples which indicate that the printed samples (with nano-sized pigment) become more darker than printed samples with micro size pigment. It is expected as by decreasing the size of dye more molecules were capture on the fabric surface and that trend is noticed in several researches (asma, hamad) $[29,39]$. From $a$ and $b$ values the colour hue changed to reddish yellow.

Table 4 also represent the colour difference $\Delta \mathrm{E}$ it is clear that there is a colour difference between the prints using nano-sized pigments and prints with micro size
Table 4 Colour strength and colour parameters of compounds 4a-d

\begin{tabular}{|c|c|c|c|c|c|c|c|}
\hline Pigment & Fabric type & $\Delta \mathrm{E}$ & $\mathrm{b}$ & a & $\mathrm{L}$ & $\mathrm{k} / \mathrm{S}$ & Pigment (4a) \\
\hline \multirow[t]{6}{*}{$4 a$} & \multirow[t]{2}{*}{ Linen } & 45.67 & 42.84 & -11.66 & 78.15 & 6.58 & Org. \\
\hline & & 47.44 & 44.8 & -10.9 & 78.82 & 11.48 & Nano. \\
\hline & \multirow[t]{2}{*}{ Polyester } & 43.10 & 40.61 & -12.41 & 80.14 & 7.95 & Org. \\
\hline & & 46.01 & 43.56 & -11.95 & 78.62 & 12.98 & Nano. \\
\hline & \multirow[t]{2}{*}{ Cotton/polyester } & 49.28 & 46.96 & -9.61 & 77.88 & 7.68 & Org. \\
\hline & & 50.97 & 48.45 & -9.1 & 74.85 & 14.05 & Nano. \\
\hline \multirow[t]{6}{*}{$4 b$} & \multirow[t]{2}{*}{ Linen } & 86.53 & 40.5 & -0.52 & 77.93 & 8.38 & Org. \\
\hline & & 87.63 & 46.96 & 11.67 & 71.74 & 12.04 & Nano. \\
\hline & \multirow[t]{2}{*}{ Polyester } & 79.66 & 21.12 & -0.47 & 77.59 & 7.32 & Org. \\
\hline & & 80.42 & 35.70 & 15.47 & 69.52 & 11.06 & Nano. \\
\hline & \multirow[t]{2}{*}{ Cotton/polyester } & 81.85 & 31.98 & -1.66 & 77.79 & 8.33 & Org. \\
\hline & & 84.12 & 40.61 & 14.08 & 69.66 & 13.94 & Nano. \\
\hline \multirow[t]{6}{*}{ 4c } & \multirow[t]{2}{*}{ Linen } & 77.39 & 16.70 & -1.73 & 77.59 & 8.91 & Org. \\
\hline & & 79.09 & 32.05 & -0.26 & 72.30 & 14.83 & Nano. \\
\hline & \multirow[t]{2}{*}{ Polyester } & 80.05 & 23.89 & -1.39 & 75.66 & 7.9 & Org. \\
\hline & & 79.34 & 18.04 & -1.28 & 77.25 & 13.16 & Nano. \\
\hline & \multirow[t]{2}{*}{ Cotton/polyester } & 79.71 & 16.7 & -1.73 & 71.74 & 8.73 & Org. \\
\hline & & 77.39 & 29.02 & 1.89 & 77.18 & 14.74 & Nano. \\
\hline \multirow[t]{6}{*}{ 4d } & \multirow[t]{2}{*}{ Linen } & 86.53 & 40.5 & -0.52 & 77.93 & 8.38 & Org. \\
\hline & & 87.63 & 46.96 & 11.67 & 71.74 & 12.04 & Nano. \\
\hline & \multirow[t]{2}{*}{ Polyester } & 79.66 & 21.12 & -0.47 & 77.59 & 7.32 & Org. \\
\hline & & 80.42 & 35.70 & 15.47 & 69.52 & 11.06 & Nano. \\
\hline & \multirow[t]{2}{*}{ Cotton/polyester } & 81.85 & 31.98 & -1.66 & 77.79 & 8.33 & Org. \\
\hline & & 84.12 & 40.61 & 14.08 & 69.66 & 13.94 & Nano. \\
\hline
\end{tabular}

Compound (4a): 2-amino-4-(4-(dimethylamino)phenyl)-6,6-dimethyl-7-oxo-5,6,7,8-tetrahydro-4H-chromene3-carbonitrile

Compound (4b) 2-amino-6,6-dimethyl-4-(5-methyl-2,3-dihydrofuran-2-yl)-7-oxo-5,6,7,8-tetrahydro-4H-chromene3-carbonitrile

Compound (4c) 2-amino-3-(benzo[d]thiazol-2-yl)-4-(4-(dimethylamino)phenyl)-6,6-dimethyl-5,6-dihydro$4 \mathrm{H}$-chromen-7(8H)-one

Compound (4d) 2-amino-3-(benzo[d]thiazol-2-yl)-6,6-dimethyl-4-(5-methyl-2,3-dihydrofuran2-yl)-5,6-dihydro-4H-chromen-7(8H)-one 
Table 5 Fastness properties of printed samples

Pigment 4a Pigment 4b Pigment 4c Pigment 4d

Washing fastness

Linen

$\begin{array}{ll}\text { Alt } & 4 \\ \text { St. } & 4-5\end{array}$

Polyester/cotton

$\begin{array}{lllll}\text { Alt. } & 4-5 & 4 & 4 & 4 \\ \text { St. } & 4 & 4-5 & 4-5 & 4-5 \\ \begin{array}{l}\text { Polyester } \\ \text { Alt. }\end{array} & 4 & 4-5 & 4 & 4-5 \\ \text { St. } & 4-5 & 4-5 & 4-5 & 4-5\end{array}$

Rubbing fastness

Linen

$\begin{array}{ll}\text { Alt } & 4 \\ \text { St. } & 4\end{array}$

Polyester/cotton

Alt. 4

St. $\quad 4$

Polyester

$\begin{array}{ll}\text { Alt. } & 4 \\ \text { St. } & 4\end{array}$

Perspiration

Linen

Alkali

Alt
St.

\section{4-5}

4-5

4-5

4-5

Acidic

$$
\text { Alt. }
$$

$4-5$

$4-5$

4-5

4-5

St.

\section{4-5}

4-5

4-5

$$
\text { 4-5 }
$$

$4-5$

4-5

Polyester/cotton

Alkali

$\begin{array}{ccccc}\text { Alt. } & 4-5 & 4-5 & 4-5 & 4-5 \\ \text { St. } & 4-5 & 4-5 & 4-5 & 4-5 \\ \text { Acidic } & & & & \\ \text { Alt } & 4-5 & 4-5 & 4-5 & 4-5 \\ \text { St. } & 4-5 & 4-5 & 4-5 & 4-5\end{array}$

Polyester

Alkali

$\begin{array}{ccccc}\text { Alt. } & 4-5 & 4-5 & 4-5 & 4-5 \\ \text { St. } & 4-5 & 4-5 & 4-5 & 4-5 \\ \text { Acidic } & & & & \\ \text { Alt. } & 4-5 & 4-5 & 4-5 & 4-5 \\ \text { St. } & 4-5 & 4-5 & 4-5 & 4-5\end{array}$

\section{Light fastness}

Linen $\quad 5-6 \quad 5 \quad 5-6 \quad 5$

Polyester/ 5-6 $55-6 \quad 5$

cotton

$5-6$

5

$5-6 \quad 5$

Alt Alternation, St Staining on cotton pigments where the pigment concentration is constant. All the prints have ranging from good to very good Fatness to rubbing washing, perspiration and light (Table 5).

\section{Conclusion}

This paper describes the preparation of benzopyran derivatives disperse dye in microwave as an eco-friendly approach and its conversion into nano size using microwave at optimum conditions.

The results obtained show that:

- The particle size diameters obtained were in the range of 25-57 $\mathrm{nm}$ for Nanoparticles of the prepared dyes, while that of the original dye particles ranges from 200 to $700 \mathrm{~nm}$.

- The nanostructure of benzopyran derivatives dyes and its application via pigment printing technique bring a series of unique properties: excellent colour fastness, good ecological performance and advanced performance and non-selectivity to various fibers provide a wide market for the product application, and provide a strong technical support to transform the traditional printing and dyeing industry with frontier technology.

Acknowledgements The authors are gratefully grateful acknowledge to National Research Centre (NRC) for facilities provided.

\section{Compliance with ethical standards}

Conflict of interest The authors declare that they have no conflict of interest.

\section{References}

1. AATCC Test Method (8-2007) (2007) Colorfastness to Crocking. Crockmeter Method vol 86. American Association of Textile Chemists and Colorists

2. AATCC Test Method (15-2013) (2013) Colour Fastness to Perspiration vol 86. American Association of Textile Chemists and Colorists

3. AATCC Test Method (16-2004) (2005) Colour Fastness to Light: outdoor vol 68. American Association of Textile Chemists and Colorists

4. AATCC Test Method (61-2007) (2007) Colour Fastness to Washing: Characterization of Textile Colorants vol 86. American Association of Textile Chemists and Colorists

5. Abd El-Rahman NM, Borik RM (2014) Eco-friendly solventfree synthesis of tetrahydrobenzo[b]pyran derivatives under microwave irradiation. World Appl Sci J 31:1-6. https://doi. org/10.5829/idosi.wasj.2014.31.01.8365 
6. Abo-Shosha MH, Nassar FA, El-Sayed Z, Hassabo AG (2009) Preparation and characterizations of some fatty acid/polyethylene glycol condensates and utilization as softeners for cotton fabric. RJTA 13:46-60

7. Abo-Shosha MH, Nassar FA, Haggag K, El-Sayed Z, Hassabo AG (2009) Utilization of some fatty acid/PEG condensates as emulsifiers in kerosene paste pigment printing. RJTA 13:65-77

8. Adeel S, Gulzar T, Azeem M, Ur Fazal R, Saeed M, Hanif I, Iqbal $\mathrm{N}$ (2017) Appraisal of marigold flower based lutein as natural colourant for textile dyeing under the influence of gamma radiations. Rad Phys Chem 130:35-39. https://doi.org/10.1016/j. radphyschem.2016.07.010

9. Adeel $\mathrm{S}$ et al. (2018) Sustainable dyeing of microwave treated polyester fabric using disperse yellow 211 dye. J Mex Chem Soc 62:1-6

10. Adeel $S$ et al (2018) Microwave assisted modulation of vat dyeing of cellulosic fiber: improvement in color characteristics. J Nat Fibers 15:517-526. https://doi.org/10.1080/15440 478.2017.1349018

11. Adeel S, Shahid S, Khan S, Rehman F, Muneer M, Zuber M, Akhtar N (2018) Eco-friendly disperse dyeing of ultraviolet-treated polyester fabric using disperse yellow 211. Pol J Environ Stud 27:1935-1939. https://doi.org/10.15244/pjoes/76033

12. Adeel S, Usman M, Haider W, Saeed M, Muneer M, Ali MJC (2015) Dyeing of gamma irradiated cotton using Direct Yellow 12 and Direct Yellow 27: improvement in colour strength and fastness properties. Cellulose 22:2095-2105. https://doi.org/10.1007/ s10570-015-0596-0

13. Ahmed KA, El-Molla MM, Abdel-Mottaleb MSA, Mohamed SA, ElSaadany S (2013) Synthesis and evaluation of novel fluorescent dyes using microwave irradiation. Res J Chem Sci 3:1-16

14. Balalaie S, Bararjanian M, Amani AM, Movassagh B (2006) (S)Proline as a neutral and efficient catalyst for the one-pot synthesis of tetrahydrobenzo[b]pyran derivatives in aqueous media. ChemInform 37:263-266

15. Bhatti IA, Adeel S, Parveen S, Zuber M (2016) Dyeing of UV irradiated cotton and polyester fabrics with multifunctional reactive and disperse dyes. J Saudi Chem Soc 20:178-184. https://doi. org/10.1016/j.jscs.2012.12.014

16. Bhatti IA, Adeel S, Siddique S, Abbas M (2014) Effect of UV radiation on the dyeing of cotton fabric with reactive blue 13. J Saudi Chem Soc 18:606-609. https://doi.org/10.1016/j. jscs.2012.11.006

17. Bhatti IA, Adeel S, Taj H (2014) Application of Vat Green 1 dye on gamma ray treated cellulosic fabric. Rad Phys Chem 102:124127. https://doi.org/10.1016/j.radphyschem.2014.04.015

18. Bouasla S, Amaro-Gahete J, Esquivel D, Lopez MI, JimenezSanchidrian C, Teguiche M, Romero-Salguero FJ (2017) Coumarin derivatives solvent-free synthesis under microwave irradiation over heterogeneous solid catalysts. Molecules 22:2072. https://doi.org/10.3390/molecules22122072

19. Chaturvedi D, Chaturvedi AK, Mishra N, Mishra V (2012) Triton-B-catalyzed efftcient, solvent-free synthesis of benzopyrans. Organic Chem Int 2012, 208948. https://doi. org/10.1155/2012/208948

20. El-Hennawi H, Mahmoud S, Ragheb A (2017) Eco-friendly coloration of silk and flax fabrics with natural dye enhanced by ultraviolet radiation. Egypt Pharm J 16:192. https://doi.org/10.4103/ epj.epj_31_17

21. El-Sayed R, Fadda AA (2016) Synthesis of pharmacological heterocyclic derivatives based surfactants. J Oleo Sci 65:929-940. https://doi.org/10.5650/jos.ess 15300

22. El-Zawahry MM, Abdelghaffar F, Abdelghaffar RA, Hassabo AG (2016) Equilibrium and kinetic models on the adsorption of Reactive Black 5 from aqueous solution using Eichhornia crassipes/chitosan composite. Carbohyd Polym 136:507-515. https://doi.org/10.1016/j.carbpol.2015.09.071

23. Ghaffar A et al (2019) Effects of microwave radiation on cotton dyeing with reactive blue 21 dye. Pol J Environ Stud 28:16871691. https://doi.org/10.15244/pjoes/84774

24. Hassabo AG (2005) Preparation, characterisation and utilization of some textile auxiliaries. MSc Thesis, El-Azhar University

25. Hassabo AG (2011) Synthesis and deposition of functional nanomaterials on natural fibres. PhD Degree, RWTH Aachen University, Germany

26. Hassabo AG, Erberich M, Popescu C, Keul H (2015) Functional polyethers for fixing pigments on cotton and wool fibres. Res Rev Polym 6:118-131

27. Hassabo AG, Mendrek A, Popescu C, Keul H, Möller M (2014) Deposition of functionalized polyethylenimine-dye onto cotton and wool fibres. RJTA 18:36-49

28. Hassabo AG, Mohamed AL (2016) Multiamine modified chitosan for removal metal ions from their aqueous solution. Biotechnol Indian J 12:59-69

29. Hebeish A, Rekaby M, Shahin AA, Ragheb AA (2016) Novel nanopigment derived from vat dyes for printing cotton fabrics. Egypt J Chem 59:99-114

30. Jin TS, Xiao JC, Wang SJ, Li TS, Song XR (2003) An efficient and convenient approach to the synthesis of benzopyrans by a three-component coupling of one-pot reaction. Synlett 2003:2001-2004

31. Kale MJ, Bhat NV (2011) Effect of microwave pretreatment on the dyeing behaviour of polyester fabric. Rev Progr Color Relat Topics 127:365-371. https://doi.org/10.111 1/j.1478-4408.2011.00332.x

32. Kamel MM, El-Shishtawy RM, Youssef BM, Mashaly HM (2005) Ultrasonic assisted dyeing, Part III: dyeing of wool with lac as a natural dye. Dyes Pigm 65:103-110. https://doi.org/10.1016/j. dyepig.2004.06.003

33. Karcı F, Ertan N (2005) Synthesis of some novel hetarylazo disperse dyes derived from 4-hydroxy-2H-1-benzopyran-2-one (4-hydroxycoumarin) as coupling component and investigation of their absorption spectra. Dyes Pigm 64:243-249

34. Khan A, Iqbal N, Adeel S, Azeem M, Batool F, Ahmad I (2014) Extraction of natural dye from red calico leaves: gamma ray assisted improvements in colour strength and fastness properties. Dyes Pigm 103:50-54. https://doi.org/10.1016/j.dyepi g.2013.11.024

35. Li JT, Xu WZ, Yang LC, Li TS (2004) One-pot synthesis of 2-mino4-aryl-3-carbalkoxy-7,7-dimethyl-5,6,7,8-tetrahydrobenzo[b] pyran derivatives catalyzed by $\mathrm{KF} /$ basic $\mathrm{Al}_{2} \mathrm{O}_{3}$ under ultrasound irradiation. Synth Commun 34:4565-4571

36. Lian X-Z, Huang Y, Li Y-Q, Zheng W-J (2008) A green synthesis of tetrahydrobenzo[b]pyran derivatives through three-component condensation using $\mathrm{N}$-methylimidazole as organocatalyst. Chem Mon 139:129-131. https://doi.org/10.1007/s0070 6-007-0706-2

37. Liu F, You QD (2007) Microwave-assisted one-pot preparation of tetrahydro-beta-carboline hydrochlorides under solventfree conditions. Synth Commun 37:3933-3938. https://doi. org/10.1080/00397910701572555

38. Majumdar N, Paul ND, Mandal S, de Bruin B, Wulff WD (2015) Catalytic synthesis of 2H-chromenes. ACS Catal 5:2329-2366. https://doi.org/10.1021/acscatal.5b00026

39. Mashaly HM, Abdelghaffar RA, Kamel MM, Youssef BM (2014) Dyeing of polyester fabric using nano disperse dyes and improving their light fastness using $\mathrm{ZnO}$ nano powder. Indian J Sci Technol 7:960-967

40. Pachamuthu K, Schmidt RR (2003) Diels-Alder reaction of 2-nitro glycals: a new route to the synthesis of benzopyrans. Synlett 2003:1355-1357 
41. Sinha K, Chowdhury S, Saha PD, Datta S (2013) Modeling of microwave-assisted extraction of natural dye from seeds of Bixa orellana (Annatto) using response surface methodology (RSM) and artificial neural network (ANN). Ind Crops Prod 41:165-171. https://doi.org/10.1016/j.indcrop.2012.04.004

42. Su W, Guo S, Hong Z, Chen R (2010) Microwave-assisted novel synthesis of amino-thieno[3,2-b]pyridines under solventfree conditions. Tetrahedron Lett 51:5718-5720. https://doi. org/10.1016/j.tetlet.2010.08.075

43. Usman M, Adeel S, Haider W, Ghaffar A, Rehman F, Ali M (2016) Dyeing of biotreated and gamma irradiated cotton fabric using direct yellow 12 and direct yellow 27. J Nat Fibers 13:483-491. https://doi.org/10.1080/15440478.2015.1066289

44. Vellingiri K, Ramachandran T, Senthilkumar P (2014) Functional characteristics of textile fabrics by plasma-nano treatment. Int J Cloth Sci Technol 26:456-479. https://doi.org/10.1108/IJCST -05-2013-0053

45. Waly A, Abou-Zeid NY, Marie MM, El-Sheikh MA, Mohamed AL (2006) Especial finishing of cotton to impart flame-retardancy and easy care finishing. Paper presented at the 3rd international conference of Textile Research Division, NRC; Textile Processing: State of the Art \& Future Developments, Cairo, Egypt, 2-4 April

46. Waly A, Marie MM, Abou-Zeid NY, El-Sheikh MA, Mohamed AL (2006) Process of single-bath dyeing, finishing and flamretarding of cellulosic textiles in presence of reactive tertiary amines. Paper presented at the 3rd international conference of Textile Research Division, NRC; Textile Processing: State of the Art \& Future Developments, Cairo, Egypt, 2-4 April
47. Waly A, Marie MM, Abou-Zeid NY, El-Sheikh MA, Mohamed $A L$ (2008) Flame retarding, easy care finishing and dyeing of cellulosic textiles in one bath. Egypt J Text Polym Sci Technol 12:101-131

48. Waly Al, Marie MM, Abou-Zeid NY, El-Sheikh MA, Mohamed AL (2012) Processes of dyeing, finishing and flame retardancy of cellulosic textiles in the presence of reactive tertiary amines. RJTA 16:66-84

49. Xue Z, Jin-xin H (2011) Improvement in dyeability of wool fabric by microwave treatment. Indian J Fibre Text Res 36:58-62

50. Yadav JS, Reddy BVS, Aruna M, Thomas M (2002) A facile synthesis of trans-fused pyrano[3,2-c]benzopyrans catalyzed by scandium triflate. Synthesis 2:217-220

51. Yu L-Q, Liu F, You Q-D (2009) One-pot synthesis of tetrahydrobenzo[b]pyran derivatives catalyzed by amines in aqueous media. Organ Prep Proced Int 41:77-82. https://doi. org/10.1080/00304940802711275

52. Zhao G-L, Shi Y-L, Shi M (2005) Synthesis of Functionalized $2 \mathrm{H}-1$-Benzopyrans by DBU-catalyzed reactions of salicylic aldehydes with allenic ketones and esters. Org Lett 7:4527-4530. https://doi.org/10.1021/ol051920v

Publisher's Note Springer Nature remains neutral with regard to jurisdictional claims in published maps and institutional affiliations. 